\title{
ASSESSMENT OF FIBROSIS INDUCED BY BLEOMYCIN IN A RAT MODEL THAT RESEMBLES ORAL SUBMUCOUS FIBROSIS
}

\author{
Dina Soliman Khater*
}

\begin{abstract}
Background and Objective: Oral submucous fibrosis (OSF) is a precancerous disease that is characterized by subepithelial fibrosis of the oral cavity. Bleomycin is a chemotherapeutic antibiotic which was used in animal models of pulmonary fibrosis as fibrosis is one of the major side effects of Bleomycin in human cancer therapy. The aim of this study was to evaluate the degree of fibrosis in OSF induced by Bleomycin in a rat model using Van-Gieson stain and studying the expression of TGF- $\beta 1$ and SMAD-3.

Materials and Methods: A total of fifty adult female albino rats were used and divided into four test groups (ten animals each) according to the duration of treatment (2, 4, 6 and 8 weeks). Another ten animals were used as control group. Bleomycin at a concentration of $1 \mathrm{mg} / \mathrm{ml}$ was maintained and was injected subcutaneously into one side of the cheek mucosa of the rats daily. Meanwhile, the rats of the control group were injected with saline. Then the dissected buccal mucosae of the rats were evaluated by H\&E stain, Van-Gieson special stain, TGF- $\beta 1$ immunostaining and determination of SMAD-3 gene level by qRT-PCR.
\end{abstract}

Results: The histological findings were similar to that of OSF in humans. The mean value of each of Van-Gieson, TGF- $\beta 1$ in addition to SMAD-3 gene expression gradually increased by time to reach its highest level at $8^{\text {th }}$ week of the experiment. Meanwhile, the lowest mean area percent was recorded in the control group.

Conclusion: The histological changes induced by Bleomycin in a rat model gave a fibrotic response similar to that of OSF in humans. Downregulation of TGF- $\beta 1 /$ SMAD-3 signaling could provide a valuable method for treatment of OSF.

KEYWORDS: Oral submucous fibrosis, Bleomycin, rat model, TGF- $\beta 1$, SMAD-3

\section{INTRODUCTION}

Oral submucous fibrosis (OSF) is a precancerous and potentially malignant disorder of the oral cavity. ${ }^{1}$ It is defined by Pindborg and Sirsat ${ }^{2}$ as a chronic insiduous disease which affects the oral cavity and sometimes the pharynx.

It was regarded as a collagen disorder that is characterized by subepithelial fibrosis of the oral

\footnotetext{
* Associate Professor, Department of Oral \& Maxillofacial Pathology, Faculty of Dentistry, Cairo University, Cairo, Egypt.
} 
cavity. ${ }^{3}$ Burning sensation occurred at first then ulceration and dryness of the mouth followed by fibrosis of the oral mucosa, blanching and trismus. ${ }^{4}$ Histopathological features of OSF revealed juxta epithelial inflammatory reaction, followed by fibroelastic change of the lamina propria, excessive collagen deposition and epithelial atrophy. This led to rigidity of the oral mucosa causing limitation of opening the mouth and difficulty in eating or maintaining oral health. ${ }^{6}$

The pathogenesis of the disease is still not confirmed yet and the disease is thought to be a multifactorial condition ${ }^{7}$; where chewing of betel quid/areca nut has been found as one of the most significant risk factors for OSF. ${ }^{8}$ It has been found that Arecoline (alkaloid component of the betel quid) played an important role in the pathogenesis of OSF as it increased the synthesis of collagen. ${ }^{9}$

Transforming growth factor-beta1 (TGF- $\beta 1$ ) is a cytokine that has a key role in inducing myofibroblastic phenotype and the regulation of the extracellular matrix assembly and its expression is increased under numerous fibrotic conditions. ${ }^{7}$ SMAD proteins are specific mediators of TGF- $\beta$ signaling pathway that is initiated by attachment of ligand to transmembranous serine/threonine kinase Type I and II receptors, which activates the cascade of SMAD signal transduction pathway. ${ }^{10,11}$ It has been reported that fibrosis in scars occurred due to the upregulation of SMAD-3 and downregulation of SMAD-7 through the TGF- $\beta 1$ pathway. ${ }^{12}$ In addition, Verrecchia et al. ${ }^{13}$ demonstrated a number of collagen gene promoters in human dermal fibroblasts which were induced by TGF- $\beta 1$ and dependent upon SMAD-3.

Animal models have been used for a while and became an important way in studying any disorder because of this complexity which can't be replicated in cell cultures or nonliving systems. Moreover, scientists all over the world encouraged using animal models in studying etiology, pathogenesis and treatment of several diseases. ${ }^{14}$ Bleomycin is a chemotherapeutic antibiotic which was used in animal models of pulmonary fibrosis as fibrosis is one of the major side effects of Bleomycin in human cancer therapy. ${ }^{15,16}$ In addition, endotracheal instillation of Bleomycin produced an animal model of pulmonary fibrosis. ${ }^{17}$ Furthermore, Bleomycin was also used for making animal model of scleroderma. ${ }^{18}$ Recently, it was used to make an animal model of OSF. ${ }^{19}$

Since the study of fibrosis is essential for studying the pathogenesis of OSF, this study was done to assess fibrosis in OSF induced in a rat model using Bleomycin through studying VanGieson staining and the expression of TGF- $\beta 1$ and SMAD-3 in attempt to bring a therapeutic method for treatment of OSF.

\section{MATERIALS AND METHODS}

\section{Animals:}

A total of fifty adult female albino rats weighing (180-200gm) were purchased from the animal experimental laboratory (Faculty of Medicine, Cairo University). They were randomly selected then divided into four test groups (ten animals each) according to the duration of treatment $(2,4,6$ and 8 weeks), in addition to ten animals as control group. They were allowed access to normal laboratory chow and drinking water. The animals were housed and caged separately in plastic cages in an air conditioned room at $22 \pm 2{ }^{\circ} \mathrm{C}$ and $55 \pm 10 \%$ humidity.

The ethical approval for undertaking this study was obtained from the Institutional Animal Care and Use Committee (CU-IACUC), Cairo University (2017/82/CU). The experimental procedure was conducted in Kasr-Elainy animal and experimental laboratory (Faculty of Medicine, Cairo University) in accordance with ethical principles for animals' research as reviewed and approved by the institutional guidelines. 
The concentration of $1 \mathrm{mg} / \mathrm{ml}$ of Bleomycin (Bleocip, Cipla LTD, India, each vial of 15 units) was maintained. Bleomycin was dissolved in $0.01 \mathrm{M}$ sterile phosphate-buffered saline (PBS) at a concentration of $1 \mathrm{mg} / \mathrm{ml} .{ }^{19}$ Using a 26 -gauge needle, $100 \mu 1$ of each concentration of Bleomycin was injected subcutaneously into one side of the cheek mucosa of the rats daily for 2-8 weeks. Meanwhile, the rats of the control group were injected with PBS only subcutaneously into the cheek mucosa. The site of injection was the right side.

Animals from each group were randomly euthanized at interval of two, four, six and eight weeks. The rats were euthanized with an overdose of chloroform then buccal mucosae of the right side were dissected.

\section{Histological examination:}

The dissected buccal mucosae were fixed in $10 \%$ formalin, treated with alcohol and then embedded in paraffin wax. Sections of $4 \mu \mathrm{m}$ thickness were made for routine haematoxylin and eosin (H\&E) staining and Van-Gieson (VG) special staining. $\mathrm{H} \& \mathrm{E}$ and $\mathrm{VG}$ staining protocols were performed as usual. Then the slides were examined under light microscope for identification of fibrosis.

\section{Immunohistochemical staining protocol:}

For immunohistochemical staining, paraffin embedded tissues were sectioned at $4 \mu \mathrm{m}$ and collected at serial sections on positive charged slides (Super Frost Plus-Menzel $\mathrm{GmbH}$ ) then they were deparaffinized and dehydrated. Antigen retrieval was performed by boiling the slides in $10 \mathrm{Mm}$ citrate buffer, $\mathrm{pH} 6.0$ for 20 minutes in a domestic microwave. Slides were left to cool for 30 minutes at room temperature. Sections were incubated in $3 \%$ hydrogen peroxide for 20 minutes, then Novocastra protein block (RE7102 Novocastra, UK) was applied for 10 minutes after which the slides were incubated with the primary mouse monoclonal antibody; anti- TGF- $\beta 1$, clone 9016.2 (Sigma-Aldrich, USA) for $30 \mathrm{~min}$. at room temperature in a humidified chamber. After rinsing twice with TBS (Tris Buffered Saline, AmrescoUSA), the sections were treated with biotinylated secondary antibody (RE7103 Novocastra, UK) then labeled with streptavidin biotin kit (RE110-k Novocastra, UK). Next, the sections were incubated in 3,3'diaminobenzidine (RE7190-k Novocastra, UK) for 5 minutes and counterstained with Mayer's hematoxylin (RE7107 Novocastra, UK).

\section{Van-Gieson staining and TGF-ß1 immunohisto- chemical staining analysis:}

The histological sections were examined using ordinary light microscope to assess the prevalence of positive TGF- $\beta 1$ immunoexpression where cells with cytoplasmic TGF- $\beta 1$ immunoexpression were considered positive. However, pink color with VanGieson stain (VG) was considered increase in collagen formation. Then, all the sections were examined by an image analyzer computer system using the software Leica Qwin 500 (Leica Microsystems Imaging Solutions Ltd, Cambridge, UK). Five random fields in each specimen were captured using a magnification (X400) to determine the area percentage of positive TGF- $\beta 1$ immunoexpression and the pink color of collagen formation in sections stained with VG. The most involved areas were selected as their representative fields. Quantitative data of the image analyzer were statistically evaluated and presented as means and standard deviation (SD) values.

\section{Gene expression of SMAD-3 by quantitative real time PCR (qRT-PCR):}

\section{Total RNA extraction}

Total RNA was extracted from tissue homogenate using SV Total RNA Isolation System (Promega, Madison, WI, USA) according to manufacturer's instruction. The RNA concentrations and purity were measured with an ultraviolet spectrophotometer. 


\section{Complementary DNA (cDNA) synthesis}

The cDNA was synthesized from $1 \mu \mathrm{g}$ RNA using SuperScript III First-Strand Synthesis System as described in the manufacturer's protocol (\#K1621, Fermentas, Waltham, MA, USA). In brief, $1 \mu \mathrm{g}$ of total RNA was mixed with $50 \mu \mathrm{M}$ oligo (dT) 20, 50 $\mathrm{ng} / \mu \mathrm{L}$ random primers, and $10 \mathrm{mM}$ dNTP mix in a total volume of $10 \mu \mathrm{L}$. The mixture was incubated at $56{ }^{\circ} \mathrm{C}$ for $5 \mathrm{~min}$, and then placed on ice for $3 \mathrm{~min}$. The reverse transcriptase master mix containing 2 $\mu \mathrm{L}$ of $10 \times \mathrm{RT}$ buffer, $4 \mu \mathrm{L}$ of $25 \mathrm{mM} \mathrm{MgCl} 2,2 \mu \mathrm{L}$ of $0.1 \mathrm{M}$ DTT, and $1 \mu \mathrm{L}$ of Superscript ${ }^{\circledR}$ III RT (200 $\mathrm{U} / \mu \mathrm{L}$ ) was added to the mixture and was incubated at $25^{\circ} \mathrm{C}$ for $10 \mathrm{~min}$ followed by $50 \mathrm{~min}$ at $50{ }^{\circ} \mathrm{C}$.

\section{Real-time quantitative PCR analysis}

Real-time PCR amplification and analysis were performed using an Applied Biosystem with software version 3.1 (Step One $\mathrm{OM}^{\mathrm{TM}}$, USA). The reaction contained SYBR Green Master Mix (Applied Biosystems), gene-specific primer pairs which were shown in table (1) and were designed with Gene Runner Software (Hasting Software, Inc., Hasting, NY) from RNA sequences from the gene bank. All primer sets had a calculated annealing temperature of $60^{\circ}$. Quantitative RT-PCR was performed in a $25-\mu \mathrm{l}$ reaction volume consisting of 2X SYBR Green PCR Master Mix (Applied Biosystems), $900 \mathrm{nM}$ of each primer and $2 \mu \mathrm{l}$ of cDNA. Amplification conditions were: $2 \mathrm{~min}$ at $50^{\circ}$, $10 \mathrm{~min}$ at $95^{\circ}$ and 40 cycles of denaturation for 15 $\mathrm{s}$ and annealing/extension at $60^{\circ}$ for $10 \mathrm{~min}$. Data from real-time assays were calculated using the $\mathrm{v} 1 \cdot 7$ sequence detection software from PE Biosystems (Foster City, CA). Relative expression of studied gene mRNA was calculated using the comparative $\mathrm{Ct}$ method. All values were normalized to beta actin which was used as the control housekeeping gene and reported as fold change over background levels detected in the diseased groups.

\section{Statistical analysis}

Statistical analysis was then performed using a commercially available software program (SPSS 19; SPSS, Chicago, IL, USA). As data was parametric, significance of the difference between groups was evaluated using one way analysis of variance (ANOVA) test and Tukey's post hoc test. The level of significance was set at $\mathrm{P} \leq 0.05$

Table (1) Gene specific primer pairs

\begin{tabular}{|c|l|}
\hline Gene & \multicolumn{1}{|c|}{ Primer sequence } \\
\hline \multirow{2}{*}{ SMAD-3 } & $\begin{array}{l}\text { Forward primer : 5'-ACCGAAATGC } \\
\text { CACGGTAGAA-3' } \\
\text { Reverse primer 5' - } \\
\text { 5'-TGGGGCTCTGCACAAA GAT-3' }\end{array}$ \\
\hline Beta actin & $\begin{array}{l}\text { Forward primer } \\
\text { (control) }\end{array}$ \\
& $\begin{array}{l}\text { Reverse primer:5'- } \\
\text { ATGTAGGCCATGAGGTCCACC-3 }\end{array}$ \\
\hline
\end{tabular}

\section{RESULTS}

\section{General observation}

Monitoring of the clinical changes by visual examination was hindered owing to the small size of the rat's oral cavity and difficulty in opening their mouths.

\section{H\&E staining}

The buccal mucosae sections of the control group stained with H\&E showed hyperplastic epithelium with few inflammatory cells in the underlying connective tissue without fibrosis (fig. 1A). On the other hand, examination of $\mathrm{H} \& \mathrm{E}$ stained buccal mucosae sections injected with Bleomycin at $2^{\text {nd }}$ week of the experiment revealed the beginning of collagen fibers deposition just beneath the surface epithelium and the presence of few inflammatory cells meanwhile mild changes in the thickness of the epithelium was observed (fig. 2A). From the $4^{\text {th }}$ to the $6^{\text {th }}$ weeks of the experiment, gradual accumulation of the collagen fiber bundles in the 
lamina propria that extended between the muscles was noticed with gradual atrophy of the epithelium (figs. 2B \& 2C). However, at the $8^{\text {th }}$ week (at the end of the experiment) thin atrophied epithelium, shortened rete pegs, increased fibrosis and atrophied muscles were observed (fig. 2D).

\section{Van-Gieson staining evaluation}

VG staining gave reddish to pink color with the collagen fibers meanwhile, the cytoplasm and muscles gave a yellowish color. The control group showed no obvious fibrosis with VG staining (fig. 1B). However, the fibrosis increased from the $2^{\text {nd }}$ week of the experiment till the $8^{\text {th }}$ week (end of the experiment) which was reflected by the increase of the pinkish color of the VG staining (fig. 3A-D).

\section{Immunohistochemical evaluation of TGF- $\beta 1$ ex- pression}

Sections of the control group showed mild TGF- $\beta 1$ immunostaining of the epithelium (fig. $1 \mathrm{C})$. The immunoexpression of TGF- $\beta 1$ was cytoplasmic which increased from the $2^{\text {nd }}$ week of the experiment till the $8^{\text {th }}$ week. The positive

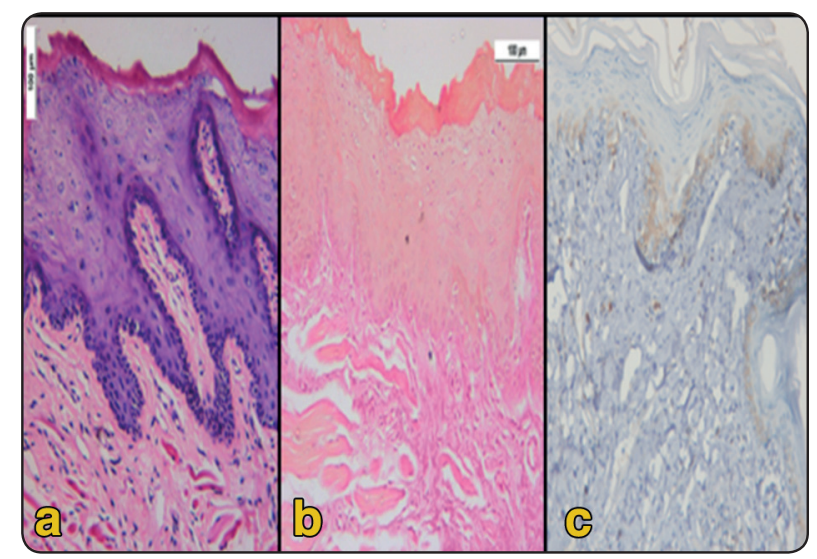

Fig. (1) Photomicrographs of the control group showing: (A) Hyperplastic epithelium and few inflammatory cells in the underlying connective tissue (H\&E, x200). (B) Mild pink color of the submucosal collagen fibers (VG, $x 200)$. (C) Mild TGF- $\beta 1$ immunostaining of the epithelium and negative TGF- $\beta 1$ immunostaining in the underlying connective tissue (TGF- $\beta 1, \mathrm{x} 200)$. immunoexpression was observed in the epithelium, subepithelial collagen fibers, endothelial cells and muscles. (fig. 4A-D)

\section{Expression of SMAD-3 by qRT-PCR}

SMAD-3 was detected in all of the studied groups. The SMAD-3 gene level expression increased in the $2^{\text {nd }}$ week of the experiment compared to the control group. Then the expression level increased gradually from the $2^{\text {nd }}$ week of the experiment till the end of the experiment at the $8^{\text {th }}$ week.

\section{Statistical analysis}

The lowest mean area percent was recorded in the control group of VG, TGF- $\beta 1$ and SMAD3 . However, the mean value gradually increased by time to reach its highest level at $8^{\text {th }}$ week of the experiment. In addition, ANOVA test revealed that the difference between the studied groups was extremely statistically significant $(\mathrm{p}<0.0001)$. (figs. $5 \& 6)$

Tukey's post hoc test revealed no significant difference between the control group and the

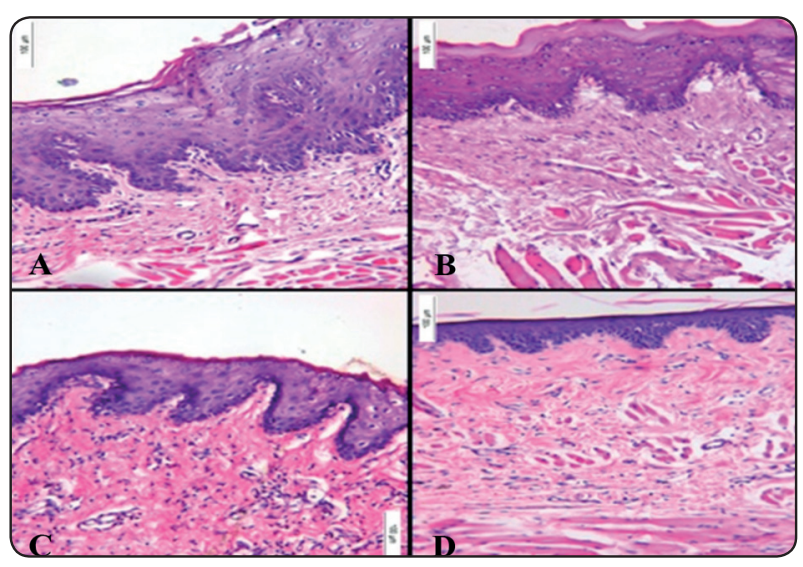

Fig. (2) Photomicrographs of rats' buccal mucosae sections after Bleomycin injection showing: (A) At the $2^{\text {nd }}$ week, beginning of subepithelial collagen deposition. (B) At the $4^{\text {th }}$ week, a slight decrease of the epithelial thickness and increase of collagen deposition between muscles. (C) At the $6^{\text {th }}$ week, thinning of the epithelium and increase of fibrosis. (D) At the $8^{\text {th }}$ week, epithelial atrophy, fibrosis and muscle atrophy (H\&E, x200 
$2^{\text {nd }}$ week of the experiment for VG and TGF- $\beta 1$. Moreover, there was no significant difference between the $6^{\text {th }}$ and the $8^{\text {th }}$ weeks; meanwhile, the mean value of TGF- $\beta 1$ at the $4^{\text {th }}$ week was not significantly different from any of the other groups

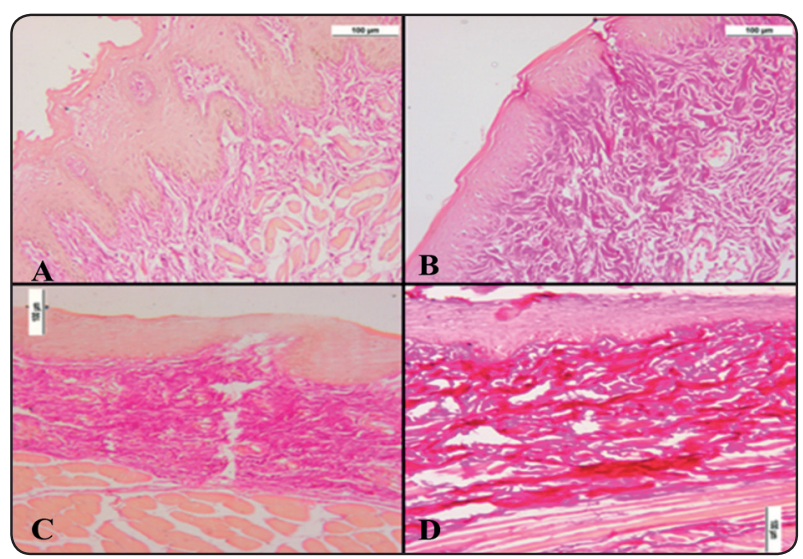

Fig. (3) Photomicrographs of the rats' buccal mucosae stained with VG showing: (A) At the $2^{\text {nd }}$ week, VG pinkish stain of the subepithelial collagen fibers. (B) At the $4^{\text {th }}$ week, the collagen formation increases giving a more pinkish color of VG stain. (C) At the $6^{\text {th }}$ week, yellowish staining of the muscles and the epithelium with VG and increased pink color of the collagen fibers. (D) At the $8^{\text {th }}$ week, strong VG staining of the collagen fibers. (VG x200)

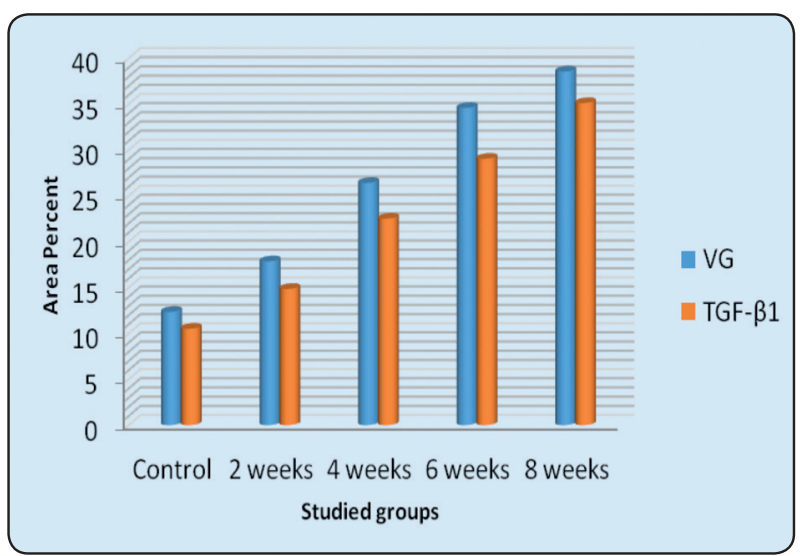

Fig. (5) Column chart showing mean area percent of VG and TGF- $\beta 1$ among studied groups. (fig.5). On the other hand, Tukey's post hoc test revealed no significant difference of SMAD-3 between $2^{\text {nd }}$ and $4^{\text {th }}$ weeks. In addition, there was no significant difference between the $6^{\text {th }}$ and the $8^{\text {th }}$ weeks. (fig.6)

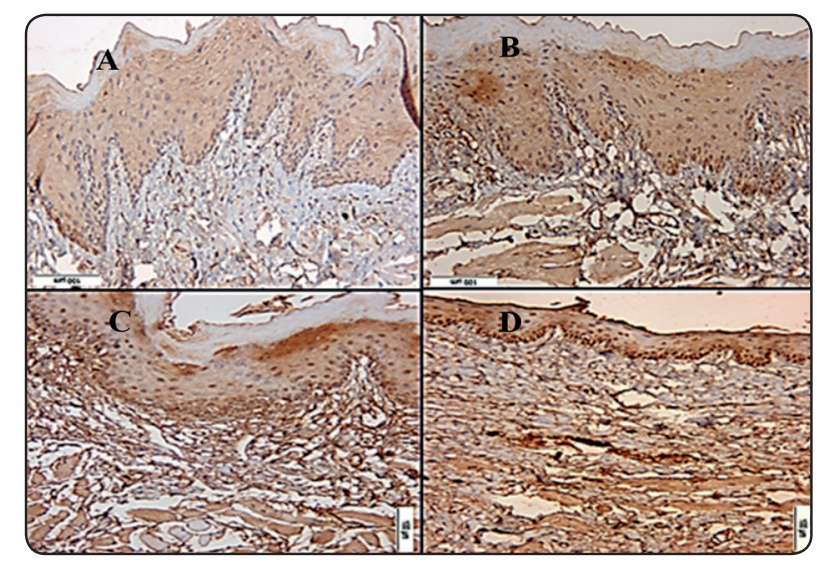

Fig. (4) Photomicrographs showing positive cytoplasmic TGF- $\beta 1$ immunoexpression showing: (A) At the $2^{\text {nd }}$ week, cytoplasmic expression of the epithelium with mild expression in the underlying connective tissue. (B) At the $4^{\text {th }}$ week, the immunostaining is in the epithelium and the underlying collagen fibers and muscles. (C) At the $6^{\text {th }}$ week, increased immunostaining of the collagen fibers and muscles. (D) At the $8^{\text {th }}$ week, strong immunostaining of the collagen fibers and in between the muscles (TGF- $\beta 1 \times 200$ )

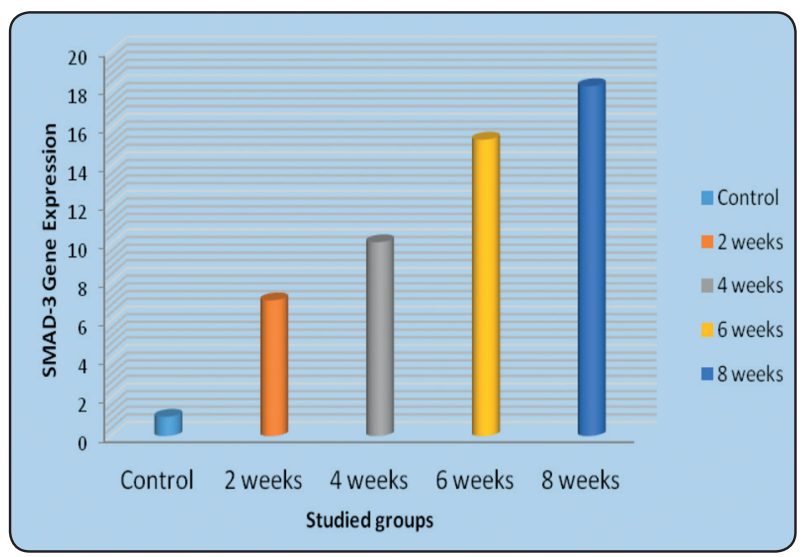

Fig. (6) Column chart showing gene expression level of SMAD3 among studied groups. 


\section{DISCUSSION}

Oral submucous fibrosis is a chronic disease in which collagen formation and fibrosis is one of its characteristic features. In the present study, Bleomycin was used to induce fibrosis in a rat model so as to mimic that of OSF and the degree of fibrosis was evaluated by Van-Gieson staining and assessement of TGF- $\beta 1$ expression and SMAD3 gene expression level in attempt to bring a therapeutic method for treatment of OSF.

In the current work, evaluation of clinical changes by visual examination was difficult due to the small size of the rat's oral cavity. However, the histological examination of the buccal mucosae sections of the rats revealed increase in subepithelial fibrosis and collagen fibers deposition starting from the $2^{\text {nd }}$ week of the experiment till reaching a higher amount at the $8^{\text {th }}$ week (at the end of the experiment). Moreover, epithelial atrophy and atrophied muscles were also observed. These findings were in agreement with the common histological features of OSF in humans. ${ }^{20,21}$ In addition, similar findings were observed by Shan-Shan et al. ${ }^{19}$ who induced OSF in a rat model by Bleomycin.

On the other hand, the buccal mucosae sections of the control group injected with saline showed hyperplastic epithelium with mild inflammatory cells in the underlying connective tissue without collagen fiber deposition. This was in accordance with Maria et al. ${ }^{22}$ who developed an animal model of OSF using areca nut and pan masala injection. The hyperplasia of the mucosal epithelium might be due to the inflammatory reaction caused by injury after saline injection.

The continuous production of collagen fibers was demonstrated in this study by VG staining which showed gradual increase in its mean value till it reached its highest level at the $8^{\text {th }}$ week of the experiment. Furthermore, an extreme statistically significant difference was observed between the studied groups. This fibrosis might be due an attempt of repair to the damage caused by irritation of the tissues after Bleomycin injection. It was reported that Bleomycin acts by causing single and double-strand DNA breaks thus interrupting the cell cycle which leads to production of DNA-cleaving superoxide and hydroxide free radicals. ${ }^{23}$ This overproduction of reactive oxygen species might lead to an inflammatory response causing activation of fibroblasts and subsequent fibrosis. ${ }^{24,25}$

The pathogenesis of OSF is not fully understood, however it has been found that this disease might result from the chemical irritation of betel quid and the mechanical irritation of the of the oral mucosa from arecanut. ${ }^{21}$ This increased collagen formation of OSF is like that formed in healing of wounds because of the irritation. Therefore, any form of injury resulting from an external factor might lead to an inflammatory process which in turns leads to fibroblast formation and fibrosis. ${ }^{26,27}$ Moreover, the localized inflammation of the mucosa might attract activated T-cells and macrophages which led to increase of cytokines as TGF- $\beta .^{3}$ One of its important isoforms is TGF- $\beta 1$ that plays a main role in wound repair and fibrosis. Furthermore, this growth factor has been reported in the development of many fibrotic diseases. ${ }^{28}$

The immunohistochemical expression of TGF$\beta 1$ in this work was observed in the buccal mucosae of all the test groups. It was observed in the epithelium, underlying collagen fibers, endothelial cells and muscles. The expression reached its highest level at the end of the experiment, at the $8^{\text {th }}$ week. Meanwhile, the control group showed no expesssion in the epithelium with mild expression in the underlying collagen fibers. These results were inconsistent with Prime et al. ${ }^{29}$ who found TGF- $\beta 1$ expression in epithelial, hemopoeitic and connective tissue cells. In addition, TGF- $\beta 1$ showed a highest value at the $6^{\text {th }}$ week in OSF induced rats by Bleomycin. ${ }^{19}$ Haque et al. ${ }^{30}$ found that TGF$\beta 1$ expression in OSF was more than that of normal. 
Moreover, it was concluded that the pathogenesis of OSF is linked to TGF- $\beta 1$ pathway which is the main initiator of collagen production. ${ }^{1,7}$

Transforming growth factor beta signaling pathway is initiated by attachment of ligand to transmembranous serine/threonine kinase Type I and II receptors, which in turn activates the cascade of SMAD signal transduction pathway. ${ }^{31}$, ${ }^{32} \mathrm{In}$ addition, a number of collagen gene promoters which were induced by TGF- $\beta 1$ and dependent upon SMAD-3 have been demonstrated in human dermal fibroblasts. ${ }^{33} \mathrm{SMAD}-3$ gene expression level increased gradually in this work from the $2^{\text {nd }}$ week till the $8^{\text {th }}$ week of the experiment. It has been reported that SMAD-3 is essential for inducing pathological fibrotic conditions. ${ }^{34}$ In addition, loss of SMAD-3 resulted in decreasing the fibrotic response in animal models. ${ }^{35}$

No statistical significant difference of both TGF- $\beta 1$ and SMAD-3 was noticed in the current study between the $6^{\text {th }}$ and the $8^{\text {th }}$ weeks of the experiment. This might be due to epithelial atrophy and diminished cells of the underlying connective tissue which is caused by the increased collagen fiber production at the end of the experiment. ${ }^{22}$

TGF- $\beta 1$ played an important role in the pathogenesis of pulmonary fibrosis by activating Smad signaling pathways. ${ }^{36}$ Furthermore, targeting TGF- $\beta 1$ or SMAD-3signaling pathways was useful in treating pulmonary fibrosis. ${ }^{37}$ Therefore; downregulation of TGF- $\beta 1 /$ SMAD-3 signaling could provide a valuable method for treatment of OSF.

In summary, fibrosis formation similar to that of OSF in humans was observed and identified in this study by the increase of both TGF- $\beta 1$ and SMAD- 3 expression and hence targeting such proteins could help in therapeutic treatment of OSF. Therefore, it is recommended to use OSF animal model to investigate the most appropriate drugs or molecular mechanisms for OSF treatment.

\section{CONCLUSION}

The histological changes induced by Bleomycin in a rat model gave a fibrotic response similar to that of OSF in humans. Downregulation of TGF- $\beta 1 /$ SMAD-3 signaling could provide a valuable method for treatment of OSF.

\section{REFERENCES}

1. Rajalalitha, P. andS., Vali, 2005. Molecular pathogenesis of oral submucous fibrosis--a collagen metabolic disorder.J. Oral Pathol. Med., 34(6):321-328.

2. Pindborg, J.J. andS.M., Sirsat, 1966. Oral submucous fibrosis. Oral Surg. Oral Med. Oral Path., 22:764-79.

3. Aziz, S.R., 2008. Oral submucous fibrosis: case report and review of diagnosis and treatment.J. Oral Maxillofac. Surg., 66(11): 2386-2389.

4. Angadi, P.V. and S.S.Rao, 2011. Areca nut in pathogenesis of oral submucous fibrosis: revisited.Oral Maxillofac. Surg., 15(1):1-9.

5. Tilakaratne, W.M., M.F., Klinikowski, T., Saku, T.J., Peters and S., Warnakuasuriya, 2006. Oral Submucous fibrosis: review on etiology and pathogenesis. Oral Oncol., 42: 561-568.

6. Rajendran, R., 2003.Oral submucous fibrosis. Oral Maxillofac. Path., 7: 1-4.

7. Kamath, V.V., K.P., Satelur,K., Rajkumar and S., Krishnamurthy, 2014. Transforming growth factor beta 1 in oral submucous flbrosis: An immunohistochemical study - Understanding the pathogenesis. J. Dent. Res, Rev., 1: 75-80.

8. Gupta, P.C., P.N., Sinor, R.B., Bhonsle, V.S., Pawar andH.C., Mehta, 1998. Oral submucous fibrosis in India: a new epidemic. Natl. Med. J., 1:113-114.

9. Canniff, J.P. andW., Harvey, 1981. The aetiology of oral submucous fibrosis: the stimulation of collagen synthesis by extracts of areca nut. Int. J. Oral Surg., 10: 163-167.

10. Sporn, M.B., 2006. The early history of TGF-beta, and a brief glimpse of its future. Cytokine Growth Factor Rev., 17:3-7.

11. Faler, B.J., R.A., Macsata, D., Plummer, L., Mishra and A.N., Sidawy, 2006. Transforming growth factor-beta and wound healing. Perspect Vasc. Surg. Endovasc. Ther., 18:55-62.

12. Khan, I., P., Agarwal, G.S., Thangjam, R., Radhesh, S.G., Rao and P., Kondaiah, 2011. Role of TGF- 3 and BMP7 
in the pathogenesis of oral submucous fibrosis. Growth Factors, 29: 119-127.

13. Verrecchia, F., M.L., Chu and A., Mauviel, 2001. Identification of novel TGF-beta/Smad gene targets in dermal fibroblasts using a combined cDNA microarray/ promoter transactivation approach. J. Biol. Chem., 276: 17058-17062.

14. Shanks, N., R., Greek and J., Greek, 2009. Are animal models predictive for humans?. Philos. Ethics Humanit Med., 15:2-4.

15. Moeller, A., K., Ask, D., Warburton, D., Gauldie and M., Kolb, 2008. The bleomycin animal model: a useful tool to investigate treatment options for idiopathic pulmonary fibrosis?. Int. J. Biochem. Cell Biol., 40(3): 362-82.

16. Limjunyawong, N., W., Mitzner andR., Horton, 2014. A mouse model of chronic idiopathic pulmonary fibrosis. Physiological Reports, 2: 1-8.

17. Chua, F., J., Gauldie and G.J., Laurent, 2005. Pulmonary fibrosis: searching for model answers. Am. J. Respir. Cell Mol. Biol., 33: 9-13.

18. Yamamoto, T., S., Takagawa, I., Katayama, K., Yamazaki, Y., Hamazaki and H. Shinkai et al., 1999. Animal model of sclerotic skin. I: Local injections of bleomycin induce sclerotic skin mimicking scleroderma. J. Invest. Dermatol., 112: 456-462.

19. Shan-Shan, Z., Z., JianGong, W., Xiong, X., Wang, Q., Min, C., Luo and T., Ling, 2016. A rat model of oral submucous fibrosis induced by Bleomycin. Oral Surg. Oral Med. Oral Path. Oral Radiol., 122: 216-223.

20. Hardie, J., 1987. Oral submucous fibrosis: a review with case reports. J. Can. Dent. Assoc., 53: 389-393.

21. Tilakaratne, W.M., M.F., Klinikowski, T., Saku, T.J., Peters and S., Warnakuasuriya, 2006. Oral Submucous fibrosis: review on etiology and pathogenesis. Oral Oncol., 42: 561-568.

22. Maria, S., V., Kamath, S., Krishnan and K., Rajkumar, 2016. Evaluation of transforming growth factor beta1 gene in oral submucous fibrosis induced in SpragueDawley rats by injections of areca nut and pan masala (commercial areca nut product) extracts.J. Cancer Res. Therap., 12: 379-385.

23. Claussen, C.A. and E.C., Long,1999. Nucleic Acid recognition by metal complexes of bleomycin. Chem. Rev., 99 (9): 2797-2816.

24. Grande, N.R., M.N., Peao, C.M., de Sá andA.P., Águas, 1998. Lung fibrosis induced by bleomycin: structural changes and overview of recent advances. Scanning Microscopy, 12(3):487-494.
25. Chaudhary, N.I., A., Schnapp andJ.E., Park, 2006. Pharmacologic Differentiation of Inflammation and Fibrosis in the Rat Bleomycin Model. Am. J. Respir. Crit. Care Med., 173(7):769-776.

26. Bishen, K.A., R., Radhakrishnan and K., Satyamoorthy, 2008. The role of basic fibroblast growth factor in oral submucous fibrosis. J. Oral Pathol. Med., 37: 402-411.

27. Yanjia, H. andJ., Xinchun, 2007. The role of epithelialmesenchymal transition in oral squamous cell carcinoma and oral submucous fibrosis. Clinica Chemica. Acta, 383: 51-56.

28. Border, W.A. andN.A., Noble, 1997. Transforming growth factor b in tissue fibrosis. N. Engl. J. Med., 331: 12861292.

29. Prime, S.S., M., Pring, M., Davies and I.C., Paterson, 2004. TGF-beta signal transduction in oro-facial health and non-malignant disease (part I). Crit. Rev. Oral Biol. Med., 15: 324-336.

30. Haque, M.F., M., Harris, S., Meghji and A.W., Barrett, 1998. Immunolocalization of cytokines and growth factors in oral submucous fibrosis. Cytokine, 10:713-719.

31. Sporn, M.B., 2006. The early history of TGF-beta, and a brief glimpse of its future. Cytokine Growth Factor Rev., 17: 3-7.

32. Faler, B.J., R.A., Macsata, D., Plummer, L., Mishra and A.N., Sidawy, 2006. Transforming growth factor-beta and wound healing. Perspect. Vasc. Surg. Endovasc. Ther., 18: 55-62.

33. Verrecchia, F., M.L., Chu and A., Mauviel, 2001. Identification of novel TGF-beta/Smad gene targets in dermal fibroblasts using a combined cDNA microarray/ promoter transactivation approach. J. Biol. Chem., 276: 17058-17062.

34. Flanders, K., 2004.Smad3 as a mediator of the fibrotic response.Int. J. Exp. Path., 85: 47-64.

35. Flanders, K.C., C.D., Major, A., Arabshahi, E., Aburime, M., Okada andM., Fujii et al., 2003. Interference with transforming growth factor-beta/ Smad3 signaling results in accelerated healing of wounds in previously irradiated skin. Am. J. Pathol., 163: 2247-2257.

36. Hu, B., Z., Wu and S.H., Phan, 2003. Smad mediates transforming growth factor-beta-induced alpha-smooth muscle actin expression. Am. J. Respir. Cell Mol. Biol., 29: 397-404.

37. Stolzenburg, L.R., S., Wachtel, H., Dang and A., Harris, 2016. miR-1343 attenuates pathways of fibrosis by targeting the TGF-beta receptors. Biochem., 473: 245-256. 